\title{
The Role of Cytokines, Adhesion Molecules, and Chemokines in Interleukin-2-induced Lymphocytic Infiltration in C57BL/6 Mice
}

\author{
James A. Anderson, ${ }^{\star}$ Alex B. Lentsch, ${ }^{\ddagger}$ Dimitri J. Hadjiminas, ${ }^{\star \|}$ Frederick N. Miller, ${ }^{\ddagger}$ Alvin W. Martin, ${ }^{\S}$ Koji Nakagawa, ${ }^{\star}$ \\ and Michael J. Edwards* \\ Departments of $*$ Surgery, ${ }^{\ddagger}$ Physiology, and ${ }^{\S}$ Flow Cytometry, J. Graham Brown Cancer Center, ${ }^{\prime}$ Veterans Administration Medical Center, \\ University of Louisville School of Medicine, Louisville, Kentucky 40292
}

\begin{abstract}
IL-2 mediates the regression of certain malignancies, but clinical use is limited because of associated toxicities, including parenchymal lymphocytic infiltration with multiple organ failure. Secondarily induced cytokines are important mediators of IL-2 toxicity and IL-2-induced lymphocyteendothelial adherence and trafficking. The recently discovered C-C chemokines, RANTES (regulated on activation, normal $\mathrm{T}$ expressed and secreted) and macrophage inflammatory protein-1 $\alpha$, have also been implicated in lymphocytic migration. We hypothesized that IL-2 alters cytokine, $\mathrm{C}-\mathrm{C}$ chemokine, and adhesion molecule expression in association with parenchymal lymphocytic infiltration. C57BL/ 6 mice were injected with $3 \times 10^{5}$ IU of IL- 2 or $0.1 \mathrm{ml}$ of $5 \%$ dextrose intraperitoneally every $8 \mathrm{~h}$ for $6 \mathrm{~d}$, then killed. IL-2 induced massive lymphocytic infiltration in the liver and lung and moderate infiltration in the kidney in association with organ edema and dysfunction. Immunostaining showed increased intercellular adhesion molecule-1 (ICAM-1) and vascular cell adhesion molecule-1 (VCAM-1) expression in association with this organ-specific lymphocytic infiltration. Flow cytometry showed increased expression of the corresponding ligands (lymphocyte function-associated antigen-1 and very late antigen-4) on splenocytes. IL-2 increased TNF- $\alpha$ mRNA and protein expression in the liver. Organs infiltrated by lymphocytes had increased TNF- $\alpha$ mRNA, whereas RANTES mRNA was increased in all organs, regardless of lymphocytic infiltration. IL-2 toxicity involves organ-specific TNF- $\alpha$ and RANTES production with increased ICAM-1 and VCAM-1 expression as potential mechanisms facilitating lymphocytic infiltration and organ dysfunction. (J. Clin. Invest. 1996. 97:1952-1959.) Key words: interleukin-2 - lymphocytes $\bullet$ cytokine $\cdot$ chemokine $•$ adhesion molecules
\end{abstract}

\section{Introduction}

IL-2 mediates the regression of certain human malignancies. Clinical trials demonstrate that response rates with IL-2 ther-

Address correspondence to Michael J. Edwards, M.D., Department of Surgery, Division of Surgical Oncology, J. Graham Brown Cancer Center, University of Louisville, Louisville, Kentucky 40292. Phone: 502-852-7827; FAX: 502-852-8031.

Received for publication 11 August 1995 and accepted in revised form 25 January 1996.

J. Clin. Invest.

(C) The American Society for Clinical Investigation, Inc.

0021-9738/96/04/1952/08 \$2.00

Volume 97, Number 8, April 1996, 1952-1959 apy for melanoma and renal cell carcinoma are superior to the best regimens of conventional chemotherapeutic agents (1). IL-2 therapy has, however, been associated with the development of systemic toxicities of sufficient severity to limit therapeutic efficacy and preclude clinical application for many patients (2). Whereas the dissociation of toxicity from antitumor efficacy for conventional chemotherapeutic agents has repeatedly proven unsuccessful over several decades, the mechanisms of toxicity of biological response modifiers are unique, and not necessarily the same as their antineoplastic mechanisms. Indeed, pentoxifylline has been shown to decrease IL-2 toxicity without affecting antitumor efficacy in a murine model (3), and antiserum to asialo ganglio- $n$-tetraosyleramide (GM1), a cell surface marker for natural killer cells (4), and anti-TNF antibody were also able to separate the efficacy from the toxicity of IL-2 therapy $(5,6)$. Thus, the possibility exists that a better understanding of the mechanisms of IL-2 toxicity may allow for an improvement in IL-2 therapeutic efficacy.

The IL-2-induced toxicities of primary clinical significance occur secondary to multiple organ edema and dysfunction in association with an IL-2-induced parenchymal lymphocytic infiltration. The mechanisms for this IL-2-induced lymphocytic infiltration and the associated multiple organ dysfunction are not completely understood. Lymphocyte-endothelial adherence and transendothelial migration are prerequisite for this massive, multiple organ lymphocytic infiltration. Whereas at least four molecular pathways of $\mathrm{T}$ cell adhesion to endothelial cells have been described (7), the adhesion of IL-2-activated lymphocytes has recently been shown to be mediated by lymphocyte function-associated antigen-1 (LFA-1) ${ }^{1}$ and very late antigen-4 (VLA-4)-related pathways in in vitro models (8). The C-C chemokines have also recently been identified as important lymphocyte chemotactic factors. Both RANTES (regulated on activation, normal $\mathrm{T}$ expressed and secreted) (9) and macrophage inflammatory protein $1-\alpha$ (MIP-1 $\alpha)(10)$ have been shown to attract T lymphocytes in in vitro models. Moreover, RANTES and MIP- $1 \alpha$ have been shown to be chemotactic for natural killer cells in vitro (11). These pathways of lymphocyte-endothelial adhesion have been extensively investigated in vitro (12), but related mechanisms of lymphocyte recruitment into various organs have rarely been studied in preclinical models of IL-2 therapy. In the current study, we hypothesized that chronic IL-2 therapy would induce the secondary cytokines TNF- $\alpha$, IL- $1 \beta$, and IFN- $\gamma$, and the C-C chemokines RANTES and MIP- $1 \alpha$, as

1. Abbreviations used in this paper: ICAM-1, intercellular adhesion molecule-1; LFA-1, lymphocyte function associated antigen-1; MIP$1 \alpha$, macrophage inflammatory protein-1 $\alpha$; RANTES, regulated on activation, normal $\mathrm{T}$ expressed and secreted; VCAM-1, vascular cell adhesion molecule-1; VLA-4, very late antigen-4. 
well as increase the expression of specific adhesion molecules in organs infiltrated by lymphocytes.

\section{Methods}

Animals. 20 female C57BL/6 mice (18-20 g) were obtained from Charles Rivers Breeding Laboratories (Wilmington, MA) and fed standard laboratory chow and water ad libitum. Mice were allowed to acclimate to their surroundings for 3 wk before the experiments. Approval for this project was obtained from the University of Louisville Animal Care and Use Committee and was in compliance with guidelines of the National Institutes of Health.

Materials. Highly purified recombinant human IL-2 with a specific activity of $18 \times 10^{6} \mathrm{IU} / \mathrm{mg}$ was a generous gift from Chiron Therapeutics (Emeryville, CA). Fluorescent labeled antibodies for flow cytometry studies were obtained from the PharMingen (San Diego, CA): PE-labeled anti-mouse LFA-1 (CD11a/CD18), FITC-labeled anti-mouse VLA-4 (CD49d), and PE- and FITC-labeled rat $\kappa \mathrm{IgG}_{2 \mathrm{~A}}$ (as isotype standards). The immunohistochemical studies were conducted with the primary antibodies: hamster anti-mouse intercellular adhesion molecule-1 (ICAM-1) (CD54) and rat anti-mouse vascular cell adhesion molecule-1 (VCAM-1) (INCAM-110) (PharMingen). The link antibodies, peroxidase-conjugated goat anti-hamster and goat anti-rat IgG, were obtained from Accurate Chemical \& Scientific Corp. (Westbury, NY). PCR primers were as follows: $\beta$-actin sense GTGGGCCGCTCTAGGCACCA, antisense CGGTTGGCCTTAGGGTTCAGGGGGG to give a 244 -base pair product; TNF- $\alpha$ sense TGAGCACAGAAAGCATGATCCGC, antisense GGTGGTTTGCTACGACGTGGGC to give a 297-base pair product; IL- $1 \beta$ sense CCAGGATGAGGACATGAGCACC, antisense TTCTCTGCAGACTCAAACTCCAC to give a 447-base pair product; IFN- $\gamma$ sense TACTGCCACGGCACAGTCATTGAA and antisense GCAGCGACTCCTTTTCCGCTTCCT to give a 405-base pair product; RANTES sense CCCTGCTGCTTTGCCTACCTCTCC and antisense TGGGTTGGCACACACTTGGCG to give a 134base pair product; and MIP- $1 \alpha$ sense GTCTCCACCACTGCCCTTGCTGTTC and antisense GCAGCAGGCAGTCGGGGTGTC to give a 618-base pair product.

Experimental design. Animals were randomly assigned to receive $0.1-\mathrm{ml}$ intraperitoneal injections of either $5 \%$ dextrose (control) or $3 \times 10^{5} \mathrm{IU}$ of IL-2 (treatment group) every $8 \mathrm{~h}$. Both groups of 10 animals received a total of 16 injections. $2 \mathrm{~h}$ after the last injection, the appearance and activity levels of mice were graded in a blinded fashion by two independent observers (J.A. Anderson and A.B. Lentsch) and scored on the following morbidity scale: $1=$ normal; $2=$ decreased activity; 3 = ruffled fur, moving only with prompting; $4=$ moribund; and 5 = dead.

At the end of the experiment, mice were anesthetized with $50 \mathrm{mg} /$ $\mathrm{kg}$ of pentobarbital intraperitoneally, and blood was obtained by cardiac puncture for a complete blood count, bilirubin, alanine transaminase, and blood urea nitrogen.

Isolation of total cellular RNA and differential PCR. Extraction of total cellular RNA was performed as described by Chomczynski and Sacchi (13). An aliquot of $400 \mathrm{ng}$ of the extracted total cellular RNA was then reverse transcribed to complementary DNA (cDNA) using the Geneamp RNA PCR protocol (Perkin-Elmer Corp., Norwalk, $\mathrm{CT}$ ) and random hexamers to prime the reverse transcriptase and any excess of deoxyribonucleotines. Amplification of the cDNA products of the PCR required $2.5 \mathrm{U}$ of AmpliTaq DNA polymerase and a final concentration of $3 \mathrm{mM} \mathrm{Mg}^{2+}$. The "hot start" technique was used (14) with one bead of ampliwax per container (Perkin-Elmer Corp.). The primers for both murine $\beta$-actin and the cytokine of interest were added in the same tube to a final concentration $0.5 \mathrm{mM}$ each.

After a 2-min initial melting at $95^{\circ} \mathrm{C}$, the mixture was amplified for a total of 30 cycles, using a three-step cycle process that began with melting at $95^{\circ} \mathrm{C}$ for $60 \mathrm{~s}$, annealing at $59^{\circ} \mathrm{C}$ for $90 \mathrm{~s}$, followed by extension at $72^{\circ} \mathrm{C}$ for $15 \mathrm{~s}$. The final cycle was followed by a $10-\mathrm{min}$ soak at $72^{\circ} \mathrm{C} .12 \mu \mathrm{l}$ of the product was electrophoresed using a 2-3.5\% MetaPhor ${ }^{\mathrm{TM}}$ agarose gel (FMC Bioproducts, Rockland, ME) in Tris-borate-EDTA buffer at $5 \mathrm{~V} / \mathrm{cm}$ for $1-3 \mathrm{~h}$. The products were then stained with $1 \mathrm{~g} / \mathrm{ml}$ ethidium bromide in Tris-borate-EDTA for $20 \mathrm{~min}$, followed by two 15-min washes in distilled water. Ultraviolet illumination was used to visualize the DNA bands, and the gels were photographed with 665 negative/positive film (Polaroid Corp., Cambridge, MA). The negative film was used for densitometry (EC apparatus model EC910 transmission densitometer; Fisher Biotechnology, Cincinnati, $\mathrm{OH}$ ), and the ratio of cytokine to $\beta$-actin mRNA was calculated for each individual organ (the heart, kidney, liver, lung) from the densities of the products and expressed as a percentage of $\beta$-actin. All primers used herein spanned at least one intron of genomic DNA. Therefore, any contaminating DNA was immediately identified since it would generate a larger than expected product.

Western blot analysis. To confirm changes in TNF- $\alpha$ mRNA as an accurate reflection of TNF- $\alpha$ protein production, we repeated the previously described experimental protocol and performed Western blot analysis on liver tissue from both control and IL-2-treated groups. Liver specimens were removed and placed in $50 \%$ glycerol in an antiproteinase buffer, snap frozen, and stored at $-70^{\circ} \mathrm{C}$. Samples were later homogenized, sonicated, and centrifuged at 100,000 $\mathrm{g}$. The cytosolic and membrane protein-rich supernatant was saved for analysis. Protein concentration was determined by a standard protein assay (Bio-Rad Laboratories, Hercules, CA) using bovine serum albumin as the standard. $50 \mu \mathrm{g}$ of total protein was separated using $15 \%$ SDS-PAGE under reducing conditions. Subsequently, proteins were transferred to a polyvinylidene difluoride membrane (Millipore Corp., Bedford, MA) and dried. Membranes were incubated with hamster anti-TNF antibodies (Genzyme Corp., Cambridge, MA) at a concentration of $10 \mu \mathrm{g} / \mathrm{ml}$ for $2 \mathrm{~h}$ at $4^{\circ} \mathrm{C}$. Membranes were then thoroughly washed and incubated with $0.18 \mu \mathrm{g} / \mathrm{ml}$ of rabbit anti-hamster $\mathrm{IgG}$ antibodies conjugated to horseradish peroxidase for $2 \mathrm{~h}$ at $4^{\circ} \mathrm{C}$. Membranes were thoroughly washed and developed, using standard enhanced chemiluminescence methods with Luminor Reagent (DuPont, Boston, MA).

Wet/dry ratios. Whole organs were removed at the end of the experiment and lightly dabbed with tissue paper before weighing. The organs were then frozen at $-20^{\circ} \mathrm{C}$ before lyophilization at $110 \mathrm{mTor}$ and $-35^{\circ} \mathrm{C}$, and then reweighed for wet/dry ratios.

Histology. Tissue samples were fixed in $10 \%$ buffered formalin. The specimens were then embedded in paraffin and sectioned before routine hematoxylin and eosin staining. Lymphocytic infiltration was graded by two observers (J.A. Anderson and A.B. Lentsch) independently in a blinded fashion according to the following four-point scale: $1=$ no infiltration; 2 = mild infiltration; $3=$ moderate infiltration; and $4=$ severely infiltrated.

Immunohistochemistry. Tissue samples were embedded in OTC compound and were snap frozen in liquid nitrogen. Sections $(5 \mu \mathrm{m})$ were cut, air dried, and fixed in acetone for $10 \mathrm{~min}$, and then air dried once more. Primary antibody (ICAM-1 diluted 1:20 or VCAM-1 diluted 1:10) was applied directly to the dry slide and incubated for $1 \mathrm{~h}$ at room temperature. After three 2-min washes in $1 \times$ automation buffer (Biomedia Corp., Foster City, CA), slides were incubated with the peroxidase-conjugated goat anti-hamster/rat IgG, diluted at 1:200 for $30 \mathrm{~min}$ (Accurate Chemical \& Scientific Corp.). Slides were then rinsed by three 2 -min washes in $1 \times$ automation buffer before peroxidase staining with Liquid DAB (Zymed Laboratories, San Francisco, CA). Sections were then washed in distilled water, lightly poststained with hematoxylin (Biomedia Corp.), rinsed with distilled water, and mounted in permount. Controls were based on slides that were prepared identically, except for the substitution of automation buffer for primary antibody. Expression of ICAM-1 and VCAM-1 was assessed by an experienced pathologist (A.W. Martin) in a blinded fashion according to the following three-point scale: $\dagger=$ mild; $\dagger \dagger=$ moderate; and $+\dagger \dagger=$ severe.

Analysis of LFA-1 and VLA-4 expression by flow cytometry. Spleens were removed and pressed through a stainless steel wire 
Table I. IL-2 Effects on Morbidity, Leukocyte, and Serum Chemistry

\begin{tabular}{lcc}
\hline \multicolumn{1}{c}{ Parameter } & Control group & IL-2 group \\
\hline Morbidity score & $1.0 \pm 0.0$ & $3.6 \pm 0.27^{*}$ \\
Lymphocyte $\left(\times 10^{3} / \mathrm{dl}\right)$ & $4.1 \pm 0.7$ & $9.1 \pm 1.5^{*}$ \\
Neutrophil $\left(\times 10^{3} / \mathrm{dl}\right)$ & $0.95 \pm 0.22$ & $10.1 \pm 1.3^{*}$ \\
Bilirubin $(\mathrm{mg} / \mathrm{dl})$ & $0.3 \pm 0.05$ & $2.4 \pm 0.87^{*}$ \\
Aspartate transaminase $(\mathrm{IU} / \mathrm{l})$ & $56.0 \pm 21.0$ & $228.0 \pm 27.0^{*}$ \\
Blood Urea Nitrogen $(\mathrm{mg} / \mathrm{dl})$ & $27.0 \pm 1.3$ & $51.6 \pm 12.9^{*}$ \\
& &
\end{tabular}

Data expressed as mean \pm SE. $* P<0.05$ by Student's $t$ test.

mesh to separate the individual cells that were suspended in PBS. All red blood cells were lysed using an ammonium chloride-EDTA solution and washed twice with PBS containing $0.1 \%$ sodium azide. The total cell count was determined with a hemocytometer, and $1 \times 10^{6}$ cells were removed for two-color direct immunofluorescence staining, followed by quantitative analysis by flow cytometry. Antibodies to murine LFA-1 (labeled with phycoerythrin, red) and VLA-4 (labeled with FITC, green) were then added to the cell pellet and incubated at room temperature for $20 \mathrm{~min}$. Isotypically matched control antibodies ( $\kappa$ chains of rat $\mathrm{IgG}_{2 \mathrm{~A}}$ ) were added to a duplicate tube. Cells were again rinsed with PBS/sodium azide solution before fixing in $1 \%$ paraformaldehyde buffer. The expression of LFA-1 and VLA- 4 on $1 \times 10^{4}$ cells from each tube was analyzed by flow cytometry on a FACScan ${ }^{\circledR}$ (Becton Dickinson Co., Rutherford, NJ). Lymphocytes were selectively gated from a plot of forward versus orthogonal light scatter to assess cell size and granularity, respectively. The red (LFA-1) and green (VLA-4) fluorescent signals from the lymphocytes were plotted on histograms (data not shown). Cells from both control and IL-2-treated groups expressed LFA-1 fluorescence greater than the isotopic control background. VLA-4 expression overlapped $50 \%$ with the isotopic control. Mean fluorescent intensity of all cells was compared between the two groups.

Cytospins of splenocyte suspension. A suspension of $5 \times 10^{5}$ splenocytes was taken, and the red blood cells were lysed with an ammonium chloride-EDTA solution before centrifugation and resuspension in $200 \mu \mathrm{l}$ of PBS. This volume was then loaded into a cytofunnel and centrifuged at $200 \mathrm{rpm}$ for $5 \mathrm{~min}$ onto charged slides using a cytospin (model 3; Shandon, Inc., Pittsburgh, PA). After allowing the suspension to dry overnight, the cytospins were stained with WrightGiemsa before counting. 200 cells from each slide were identified as either small or large lymphocytes, eosinophils, polymorphonuclear cells, or macrophages. The results were expressed as a percentage of cells counted.

\section{Results}

Our data showed significant morbidity in the IL-2-treated group compared with the control group (Table I). The well-
Table II. Percentage of Organ-specific Cytokine and Chemokine mRNA Levels

\begin{tabular}{lcccccc}
\hline & \multicolumn{3}{c}{ Secondary cytokines } & & \multicolumn{2}{c}{ Chemokines } \\
\cline { 2 - 3 } \cline { 6 - 7 } Organ & TNF- $\alpha$ & IL-1 $\beta$ & IFN- $\gamma$ & & RANTES & MIP-1 $\alpha$ \\
\hline Liver & & & & & \\
$\quad$ Control & $4.3 \pm 1.7$ & $1.6 \pm 0.5$ & $1.1 \pm 0.4$ & & $2.6 \pm 0.5$ & $17.0 \pm 6.9$ \\
$\quad$ IL-2 & $16.6 \pm 3.4^{*}$ & $5.5 \pm 1.5^{*}$ & $1.1 \pm 0.9$ & & $64.5 \pm 2.5^{*}$ & $0.0 \pm 0.0^{*}$ \\
Lung & & & & & \\
$\quad$ Control & $1.5 \pm 1.1$ & $0.2 \pm 0.1$ & $9.3 \pm 2.8$ & & $10.5 \pm 4.4$ & $43.0 \pm 21.1$ \\
$\quad$ IL-2 & $11.2 \pm 1.4^{*}$ & $5.3 \pm 1.1^{*}$ & $7.3 \pm 2.7$ & & $63.0 \pm 1.7^{*}$ & $2.2 \pm 2.0^{*}$ \\
Kidney & & & & & \\
$\quad$ Control & $0.0 \pm 0.0$ & $0.0 \pm 0.0$ & $4.0 \pm 1.0$ & & $14.3 \pm 1.2$ & $13.9 \pm 2.5$ \\
IL-2 & $3.4 \pm 0.9^{*}$ & $0.0 \pm 0.0$ & $0.6 \pm 0.4^{*}$ & & $51.1 \pm 3.2^{*}$ & $15.3 \pm 2.6$ \\
Heart & & & & & \\
$\quad$ Control & $2.5 \pm 0.9$ & $0.0 \pm 0.0$ & $7.1 \pm 1.8$ & & $11.5 \pm 1.9$ & $12.6 \pm 3.1$ \\
IL-2 & $3.6 \pm 0.71$ & $0.0 \pm 0.0$ & $2.5 \pm 0.8^{*}$ & & $47.5 \pm 3.0^{*}$ & $10.3 \pm 3.2$ \\
& & & & &
\end{tabular}

Data expressed as percentage of $\beta$-actin $( \pm \mathrm{SE}) .{ }^{*} P<0.05$ by Student's $t$ test.

known rebound leukocytosis of IL-2 treatment consisted of a significant increase in both circulating lymphocytes and neutrophils. IL-2 caused significant splenomegaly as determined by the increased size and wet weight of the spleen in the treated group $(80 \pm 4 \mathrm{mg}$ in controls vs $200 \pm 5 \mathrm{mg}$ in the IL-2treated group). Liver dysfunction in the IL-2 group was evident by a significant increase in bilirubin and aspartate transaminase, and azotemia was noted by a significant increase in blood urea nitrogen. Pleural effusions were consistently found in the IL-2-treated group but not in the control group.

Organ-specific changes in cytokine and chemokine mRNA were measured (Table II, Fig. 1). Of the three cytokines, TNF- $\alpha$ mRNA in the IL-2-treated animals most closely correlated with lymphocytic infiltration. The greatest amounts of TNF- $\alpha$ mRNA were found in the liver and lung, with a moderate increase in the kidney and no significant increase in the heart tissue. Western blot analysis on liver tissue from control and IL-2-treated mice confirmed increased amounts of TNF- $\alpha$ protein in IL-2-treated animals compared with controls (Fig. 2 ). IL-1 $\beta$ levels were also significantly increased in the liver and lung of the IL-2 group compared with controls, but were undetectable in the kidney or heart of both the treatment and control groups. IFN- $\gamma$ levels were unchanged in the liver and lung but significantly decreased in the kidney and heart after IL-2 treatment. The chemokine RANTES was dramatically increased in all organs after IL-2 treatment, including the heart,

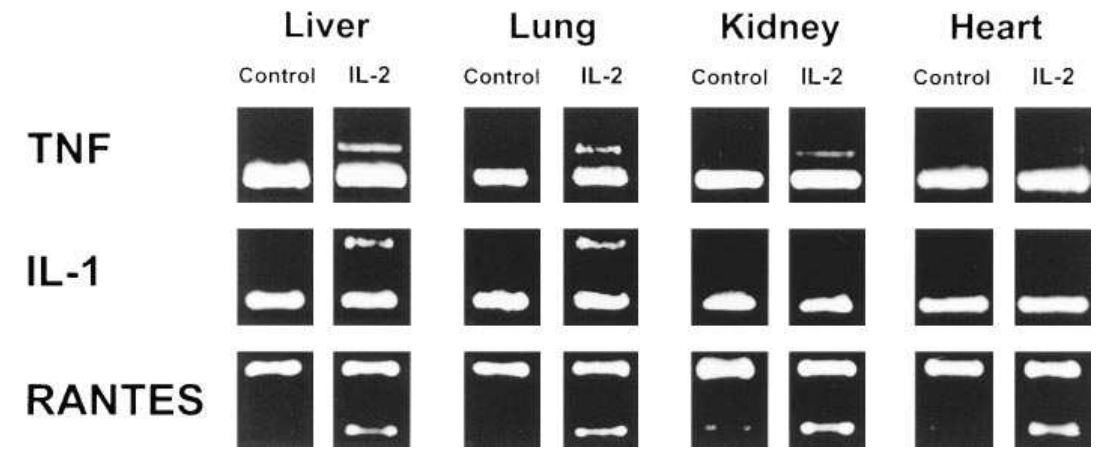

Figure 1. Representative examples of mRNA for TNF- $\alpha$, IL-1 $\beta$, and RANTES mRNA in liver, lung, kidney, and heart. Thick bands in each example are the internal control $\beta$-actin. TNF- $\alpha$ mRNA was greatly increased in the liver and lung, moderately increased in the kidney, and not increased in the heart of IL-2-treated animals. IL-1 $\beta$ mRNA was increased in the liver and lung of IL-2-treated animals but undetectable in the kidney or heart. RANTES mRNA levels were increased in all organs after IL-2 treatment. (The corresponding data for all animals are shown in Table II.) 


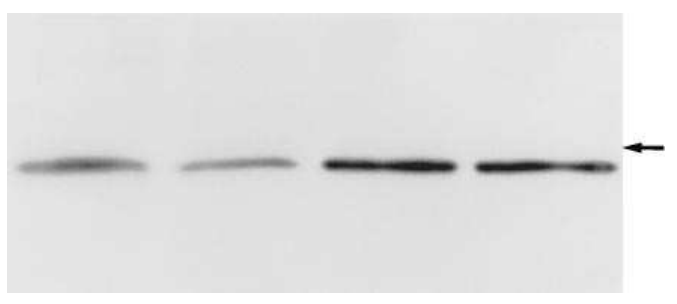

Figure 2. Western blot of TNF- $\alpha$ from the livers of control and IL-2treated mice. Bands from the IL-2-treated animals (two lanes on the right) clearly show an increase in TNF- $\alpha$ when compared with control animals (two lanes on the left). IL-2 increased protein expression of the soluble $17-\mathrm{kD}$ form of TNF- $\alpha$. The arrow indicates a molecular weight of $21.5 \mathrm{kD}$

which showed no lymphocytic infiltration. MIP-1 $\alpha$ levels significantly decreased in the liver and lung after IL-2 treatment but were unchanged in the kidney or heart. Fig. 1 illustrates representative examples of PCR for TNF- $\alpha$, IL- $1 \beta$, and RANTES mRNA in liver, lung, kidney, and heart.

Table III summarizes the effects of IL-2 on organ edema, lymphocytic infiltration, and tissue adhesion molecule up-regulation. IL-2 caused significant edema in the liver, lung, and kidney. The heart muscle was not assessed because of the lack of tissue. Significant increases in both ICAM-1 and VCAM-1 expression were seen in tissues that had significant lymphocytic infiltration after IL-2 treatment, but not in the heart, which had no lymphocytic infiltration in the IL-2 group (Fig. 3).

Flow cytometry data showed a large increase in LFA-1 expression, and a smaller but still significant increase in VLA-4 expression in splenocytes from the IL-2-treated group compared with controls (Fig. 4). A two-parameter fluorescent plot of LFA-1 and VLA-4 revealed a subset of cells that simultaneously expressed both adhesion molecules at a greater den-

Table III. Edema, Lymphocytic Infiltration, and ICAM-1 and VCAM-1 Up-Regulation

\begin{tabular}{|c|c|c|c|c|}
\hline Organ & Edema & $\begin{array}{l}\text { Lymphocytic } \\
\text { infiltration }\end{array}$ & ICAM-1 & VCAM-1 \\
\hline & wet/dry ratio & grade & grade & grade \\
\hline \multicolumn{5}{|l|}{ Liver } \\
\hline Control & $2.9 \pm 0.05$ & 1 & $\dagger$ & $\dagger$ \\
\hline IL-2 & $3.9 \pm 0.05^{*}$ & 4 & $+t^{+}$ & $\dagger^{\ddagger}$ \\
\hline \multicolumn{5}{|l|}{ Lung } \\
\hline Control & $4.3 \pm 0.05$ & 1 & $\dagger$ & $\dagger$ \\
\hline IL-2 & $4.7 \pm 0.07 *$ & 4 & $+t^{+}$ & $\dagger^{*}$ \\
\hline \multicolumn{5}{|l|}{ Kidney } \\
\hline Control & $3.6 \pm 0.05$ & 1 & $\dagger$ & $\dagger$ \\
\hline IL-2 & $4.2 \pm 0.08 *$ & 3 & $t^{+}$ & $t^{+}$ \\
\hline \multicolumn{5}{|l|}{ Heart } \\
\hline Control & N/A & 1 & $\dagger$ & $\dagger$ \\
\hline IL-2 & N/A & 1 & $\dagger$ & $\dagger$ \\
\hline
\end{tabular}

Edema is expressed as wet/dry weight ratio $( \pm \mathrm{SE})$. Lymphocytic infiltration and ICAM-1 and VCAM-1 are expressed as median grade (1-4). ICAM and VCAM expression are expressed as median grade $(\dagger-\dagger \dagger \dagger)$. ${ }^{*} P<0.05$ by Student's $t$ test. ${ }^{\ddagger} P<0.05$ by Wilcoxon's rank sum test. N/A, not assessed. sity than the control group. A representative example of a control and an IL-2-treated animal is shown in Fig. 5. A plot of forward versus side scatter of light of the splenocytes showed that the IL-2-treated group contained a subset of larger, more granulated lymphocytes, which are likely to be natural killer cells (15). The large granular lymphocytes induced by IL-2 treatment are also the splenocytes that express higher amounts of the adhesion molecules LFA-1 and VLA-4 on their surface. The morphology of the splenocytes was also assessed histologically (Table IV), confirming a relative increase in large lymphocytes compared with small lymphocytes in the IL-2treated group, which is consistent with a relative increase in natural killer cells. Polymorphonuclear leukocytes, eosinophils, and macrophages were also proportionately increased in the spleens of IL-2-treated animals.

\section{Discussion}

Multiple in vitro (7-10) and in vivo studies of delayed-type hypersensitivity (16-18) have examined various cytokines and adhesion molecules in lymphocyte migration, but we believe ours is the first to identify the combined role of cytokines, chemokines, and adhesion molecules in IL-2-induced lymphocytic infiltration.

The cytokine TNF- $\alpha$ has been implicated in IL-2 toxicity in vitro (19) and is increased in the sera of patients receiving IL-2 therapy (20). Dubinett et al. (21) recently demonstrated that in situ up-regulation of TNF- $\alpha$ mRNA expression is associated with lymphocytic accumulation and pulmonary vascular leak in the lungs of IL-2-treated mice. We show that tissue TNF- $\alpha$ mRNA levels correlate with lymphocytic infiltration in the liver and kidney as well as the lungs, and confirm the presence of TNF- $\alpha$ protein in the liver.

The cytokine IL-1 $1 \beta$ has been shown to induce ICAM-1 in vitro (22) and to increase T lymphocyte binding to endothelial cell monolayers (23). We found that IL-1 $\beta$ was increased in the liver and lung of IL-2-treated mice, but that IL-1 $\beta$ was undetectable in the murine kidney and heart. This suggests that IL-1 $\beta$ contributed to the massive lymphocytic infiltration into the liver and lung, and its absence in the kidney may explain the overall moderate infiltration seen despite the increased TNF- $\alpha$ in the kidney.

IFN- $\gamma$ production has also been shown to increase with IL-2, to induce ICAM-1 production (22), and to influence lymphocyte migration in vitro (24), but little is known about tissue-specific IFN- $\gamma$ production induced by $\operatorname{IL}-2(25,26)$. In our in vivo model, IL-2 did not increase IFN- $\gamma$ in the liver and lung and showed a significant decrease in the kidney and heart of IL-2-treated animals. The reduced IFN- $\gamma$ mRNA in the kidney and heart may be related to the decreased lymphocytic infiltration in these organs. Populations of tissue macrophages are not uniform among various tissues (27). Since tissue macrophages are the primary source of parenchymal IFN- $\gamma$, these findings also provide further evidence that the macrophage response to IL-2 is organ specific.

Lymphocyte integrin expression in dermal lymphocytic infiltration induced by a specific antigen is significantly inhibited by mAbs to either the LFA-1 (16) or VLA-4 (17), or both (18). Our analysis of LFA-1 and VLA-4 integrins showed that both were increased on the surface of these activated lymphocytes in response to IL-2. 

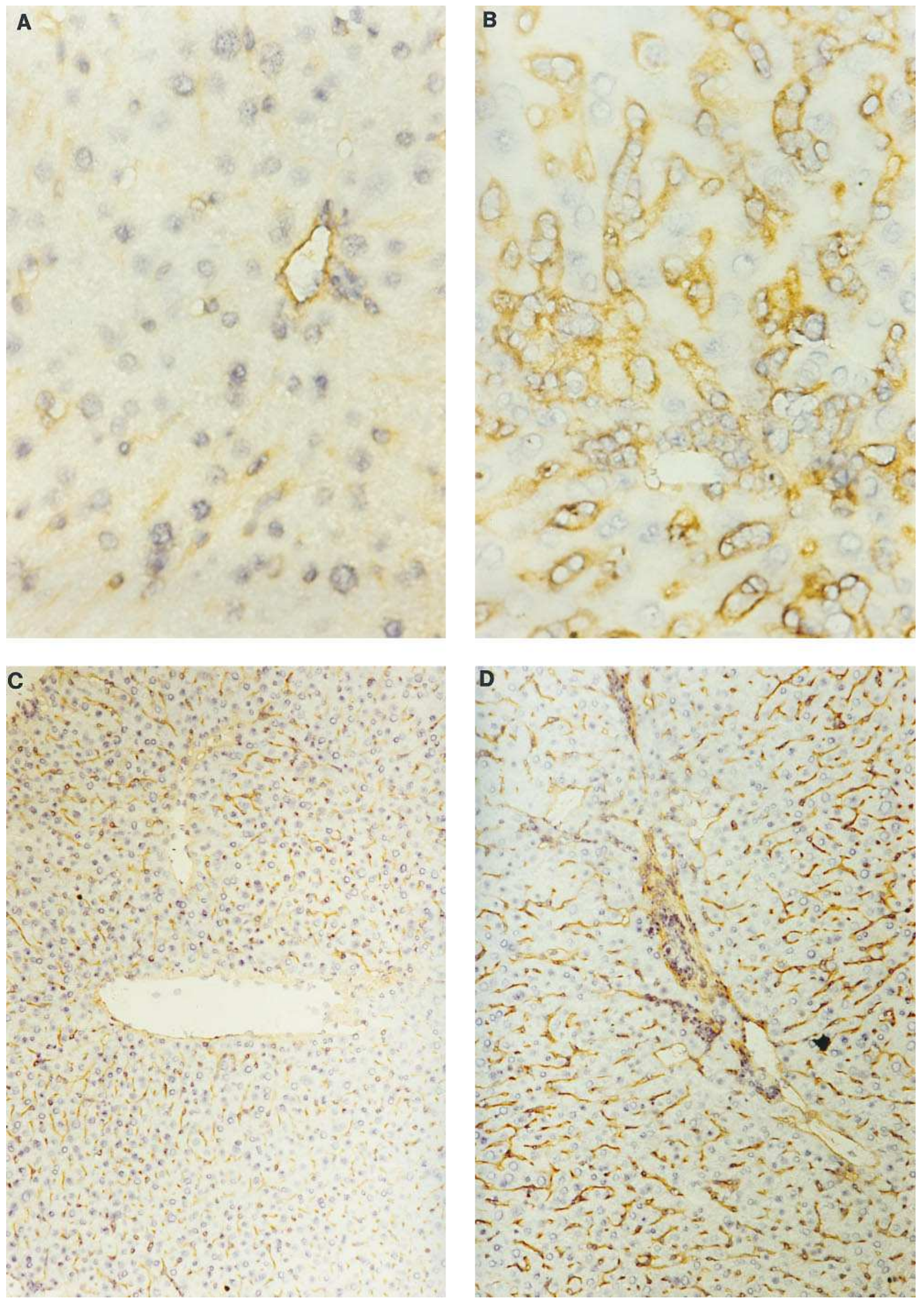

Figure 3. Representative immunohistochemistry for ICAM-1 ( $A$, control; $B$, IL-2 treated) and VCAM-1 ( $C$, control; $D$, IL-2 treated) for the liver. Expression of both ICAM-1 and VCAM-1 was increased in IL-2-treated organs with increased lymphocytic infiltration. 
LFA-1

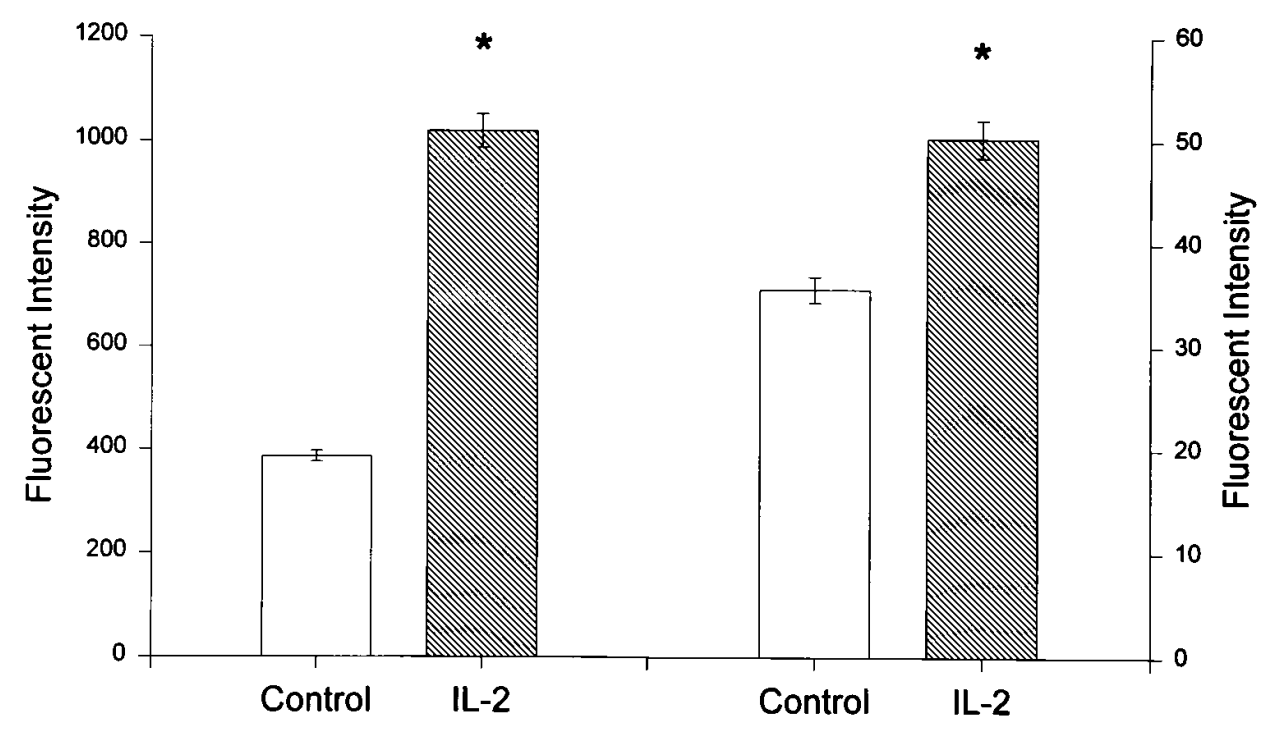

VLA-4

Figure 4. Histogram of LFA-1 and VLA-4 expression on splenocytes. $* P<0.05$ by Student's $t$ test.
The complementary ligands to LFA-1 and VLA-4 are ICAM-1 and VCAM-1, respectively. Briscoe et al. (28) found that endothelial VCAM-1 expression contributes to T cell extravasation at the sites of inflammation, and that subcutaneous TNF selectively promotes VCAM-1 expression on postcapillary venules. TNF- $\alpha$ causes up-regulation of ICAM-1 in the lung (29). In addition, mAbs to VCAM-1 inhibit lymphocyte accumulation in delayed-type hypersensitivity in skin (30). Our observations of an increased expression of ICAM-1 and VCAM-1 in the organs of animals treated with IL-2 are in accordance with current models of contact hypersensitivity (16-18).

The C-C chemokines, including MIP-1 $\alpha$ and RANTES, have been implicated in lymphocyte adhesion and trafficking $(31,32)$. MIP- $1 \alpha$ is released by activated T cells and attracts activated lymphocytes, including $\mathrm{CD}^{+}$cytotoxic $\mathrm{T}$ cells $(33,34)$. The literature regarding the functions of MIP- $1 \alpha$, however, remains unclear. Recently, Zhou et al. (35) have shown that ex-
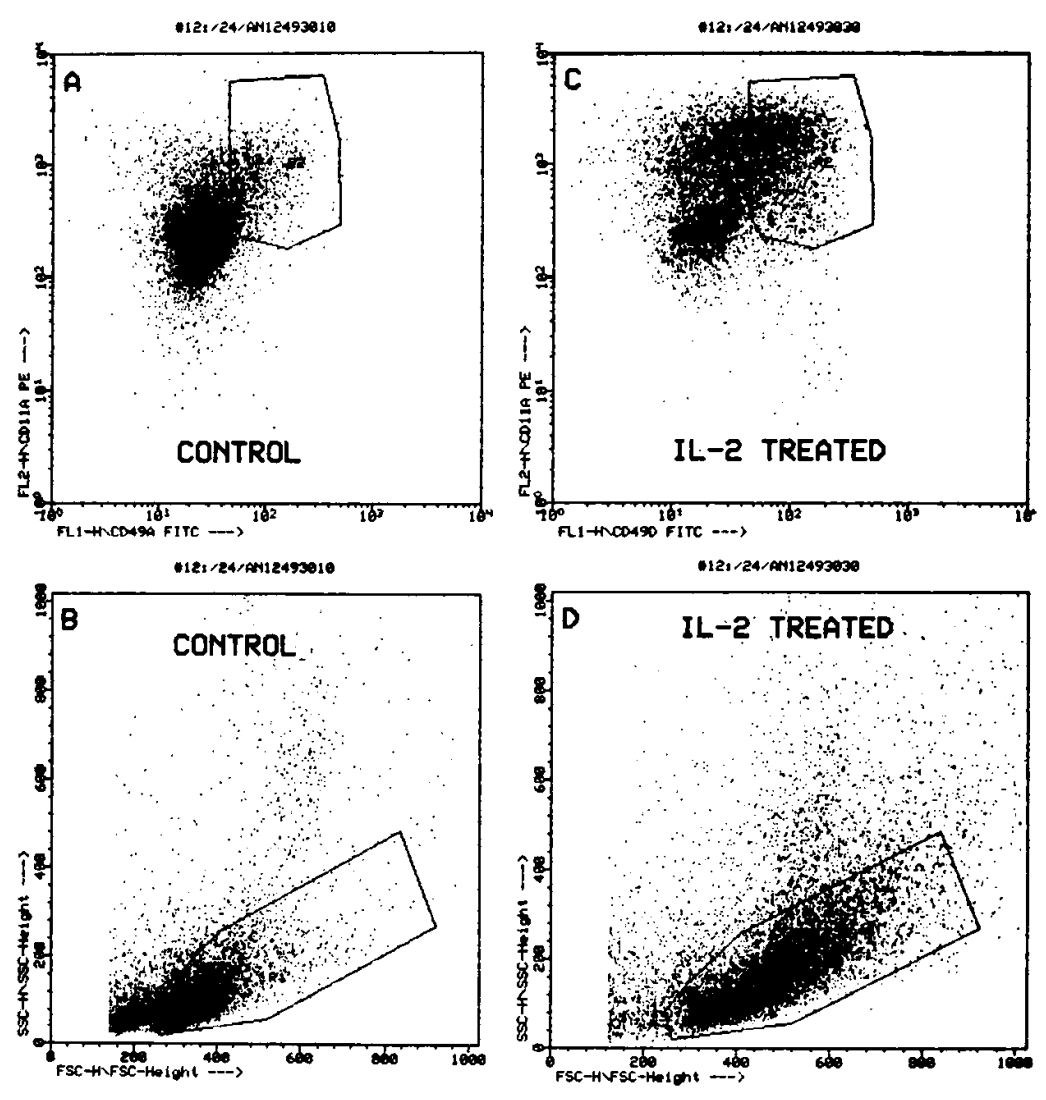

Figure 5. Representative examples of flow cytometry data ( $A$ and $B$ are from a control animal, and $C$ and $D$ are from an IL-2-treated animal). $A$ and $C$ are fluorescence plots of LFA- 1 versus VLA- 4 and show that the subset of lymphocytes induced by IL-2 treatment have increased expression of both LFA-1 and VLA-4. $B$ and $D$ are plots of forward versus side scatter (which give information on cell size and granularity, respectively) and show a subset of larger, more granular lymphocytes in the IL-2-treated animals. 
Table IV. Cytospins from Splenocyte Preparations

\begin{tabular}{lrr}
\hline & Control group & IL-2 group \\
\hline Small lymphocytes & $84.2 \pm 2.0$ & $53.7 \pm 1.9^{*}$ \\
Large lymphocytes & $10.4 \pm 1.6$ & $29.4 \pm 1.3^{*}$ \\
Eosinophils & $1.2 \pm 0.3$ & $4.2 \pm 0.6^{*}$ \\
Polymorphonuclear leukocytes & $3.5 \pm 1.0$ & $9.5 \pm 1.5^{*}$ \\
Macrophages & $0.35 \pm 0.2$ & $1.75 \pm 0.4^{*}$ \\
\hline
\end{tabular}

Data are expressed as percentage of cells $( \pm \mathrm{SE}) . * P<0.05$ by Student's $t$ test.

ogenous MIP-1 $\alpha$ in a cell culture system can inhibit T cell proliferation and activity. MIP- $1 \alpha$ production may also be inhibited by other secondarily induced cytokines. Maltman et al. (36) showed that TGF- $\beta$ can inhibit MIP- $1 \alpha$ gene expression by bone marrow macrophages. Our studies suggest that MIP-1 $\alpha$ is not the primary chemoattractant for IL-2-induced lymphocytic infiltration. Despite the well-recognized IL-2 activation of T lymphocytes, we did not find increased MIP- $1 \alpha$ in organs infiltrated by lymphocytes in our in vivo studies. In fact, IL-2 treatment resulted in a significant reduction in MIP- $1 \alpha$ mRNA in liver and lung tissues, whereas no significant alteration was seen in the kidney or heart.

RANTES is specifically chemotactic for T cells, monocytes, and eosinophils, and is maximally produced by $\mathrm{T}$ cells, fibroblasts, and renal mesangial cells a few days after activation by inflammatory mediators such as TNF- $\alpha$ and IL- $1 \beta$ (37, 38). We show that RANTES mRNA is increased in multiple organs after IL-2 treatment but cannot alone account for the observed pattern of lymphocytic infiltration, since all tissues studied showed similar increases in RANTES but had markedly varying degrees of lymphocytic infiltration. RANTES may play a "promoter" role in the chemoattraction of IL-2activated lymphocytes, but it requires a prerequisite secondary cytokine (TNF and/or IL-1 $\beta$ ) for migration to occur.

IL-2 induces organ-specific lymphocytic infiltration and the coordinated production of TNF- $\alpha$ and IL-1 $\beta$. These data suggest a role for the endothelial expression of ICAM-1 and VCAM-1, their corresponding ligands (LFA-1 and VLA-4), and RANTES expression as further possible mechanisms for this organ-specific lymphocytic infiltration.

\section{Acknowledgments}

The authors are grateful to Sherri Matthews and Margaret Abby for their help in preparing this manuscript. We thank Chiron Therapeutics (Emeryville, CA) for providing the IL-2.

This work was supported by a grant from the National Institutes of Health (CA 57527).

\section{References}

1. Rosenberg, S.A., M.T. Lotze, J.C. Yang, P.M. Aerbersold, W.M. Linehan, C.A. Seipp, and D.E. White. 1989. Experience with the use of high-dose interleukin-2 in the treatment of 652 cancer patients. Ann. Surg. 210:474-485.

2. Siegel, J.P., and R.K. Puri. 1991. Interleukin-2 toxicity. J. Clin. Oncol. 9: 694-704.

3. Edwards, M.J., B.T. Heniford, E.A. Klar, K.W. Doak, and F.N. Miller. 1992. Pentoxifylline inhibits interleukin-2-induced toxicity in C57BL/6 mice but preserves antitumor efficacy. J. Clin. Invest. 90:637-641.

4. Young, W.W., S. Hakomori, J. Durdik, and C.S. Henney. 1980. Identifi- cation of 9 ganglio- $n$-tetraosylceramide as a new cell surface marker for murine natural killer (NK) cells. J. Immunol. 124:199-201.

5. Anderson, T.D., T.J. Hayes, M.K. Gately, J.M. Bontempo, L.L. Stern, and G.A. Truitt. 1988. Toxicity of human recombinant interleukin-2 in the mouse is mediated by interleukin-activated lymphocytes: separation of efficacy and toxicity by selective lymphocyte subset depletion. Lab. Invest. 59:598-612.

6. Fraker, D.L., H.N. Langstein, and J.A. Norton. 1989. Passive immunization against tumor necrosis factor partially abrogates interleukin 2 toxicity. $J$. Exp. Med. 170:1015-1020.

7. Shimizu, Y., W. Newman, T.V. Gopal, K.J. Horgan, N. Graber, L.D. Beall, G.A. van Seveter, and S. Shaw. 1991. Four molecular pathways of T cell adhesion to endothelial cells: roles of LFA-1, VCAM-1, and ELAM-1 and changes in pathway hierarchy under different activation conditions. J. Cell Biol. 113:1203-1212.

8. Pankonin, G., B. Reipert, and A. Ager. 1992. Interactions between interleukin-2-activated lymphocytes and vascular endothelium: binding to and migration across specialized and non-specialized endothelia. Immunology. 77:5160.

9. Schall, T.J., K. Bacon, K.J. Toy, and D.V. Goeddel. 1990. Selective attraction of monocytes and T lymphocytes of the memory phenotype by cytokine RANTES. Nature (Lond.). 347:669-671.

10. Schall, T.J., K. Bacon, R.D. Camp, J.W. Kaspari, and D.V. Goeddel. 1993. Human macrophage inflammatory protein alpha (MIP-1 $\alpha$ ) and MIP- $1 \alpha / \beta$ chemokines attract distinct populations of lymphocytes. J. Exp. Med. 177:18211826.

11. Maghazachi, A.A., A. Al-Aoukaty, and T.J. Schall. 1994. C-C chemokines induce the chemotaxis of NK and IL-2-activated NK cells. J. Immunol. 153:4969-4977.

12. Bianchi, G., M. Sironi, E. Ghibaudi, C. Selvaggini, M. Elices, P. Allavena, and A. Mantovani. 1993. Migration of natural killer cells across endothelial cell monolayers. J. Immunol. 151:5135-5144.

13. Chomczynski, P., and N. Sacchi. 1987. Single-step method of RNA isolation by acid guanidinium thiocyanate-phenol-chloroform extraction. Anal. Biochem. 162:156-159.

14. Chou, Q., M. Russell, D.E. Birch, J. Raymond, and W. Bloch. 1992. Prevention of pre-PCR mis-priming and primer dimerization improves low-copynumber amplifications. Nucleic Acids Res. 20:1717-1723.

15. Kumagai, K., K. Itoh, R. Suzuki, S. Hinumo, and F. Saitoh. 1982. Studies of murine large granular lymphocytes: identification as effector cells in natural killer and T cytotoxicity. J. Immunol. 129:388-394.

16. Chisholm, P.L., C.A. Williams, and R.R. Lobb. 1993. Monoclonal antibodies to the integrin a-4 subunit inhibit the murine contact hypersensitivity response. Eur. J. Immunol. 23:682-688.

17. Scheynius, A., R.L. Camp, and E. Pure. 1993. Reduced contact sensitivity reactions in mice treated with monoclonal antibodies to leukocyte functionassociated molecule-1 and intercellular adhesion molecule-1. J. Immunol. 150: $655-663$.

18. Issekutz, T.B. 1993. Dual inhibition of VLA-4 and LFA-1 maximally inhibits cutaneous delayed-type hypersensitivity-induced inflammation. Am. J. Pathol. 143:1286-1293.

19. Nedwin, G., L. Svedersky, T. Bringman, M. Palladino, and D. Goeddel. 1985. Effect of interleukin-2, interferon- $\gamma$, and mitogens on the production of tumor necrosis factor $\alpha$ and $\beta$. J. Immunol. 135:2492-2497.

20. Mier, J.W., G. Vachino, J.W.M. Van Der Meer, R.P. Numerof, S. Adams, J.G. Cannon, H.A. Bernheim, M.B. Atkins, D.R. Parkinson, and C.A. Dinarello. 1988. Induction of circulating tumor necrosis factor (TNF $\alpha)$ as the mechanism for the febrile response to interleukin-2 (IL-2) in cancer patients. $J$. Clin. Immunol. 8:426-436.

21. Dubinett, S.M., M. Huang, A. Lichtenstein, W.H. McBride, J. Wang, G. Markovitz, D. Kelley, W.W. Grody, L.E. Mintz, and S. Dhanani. 1994. Tumor necrosis factor- $\alpha$ plays a central role in interleukin-2-induced pulmonary vascular leak and lymphocytic accumulation. Cell. Immunol. 157:170-180.

22. Dustin, M.L., R. Rothlein, A.K. Bhan, C.A. Dinnarello, and T.A. Springer. 1986. Induction by IL- $1 \beta$ and interferon- $\gamma$ : tissue distribution, biochemistry, and function of a natural adherence molecule (ICAM-1). J. Immunol. 137:245-254.

23. Cavender, D.E., D.O. Haskard, B. Joseph, and M. Ziff. 1986. Interleukin 1 increases the binding of human B and T lymphocytes to endothelial cell monolayers. J. Immunol. 136:203-207.

24. Bacon, K.B., A. Gearing, and R. Camp. 1990. Induction of in vitro human lymphocyte migration by interleukin-3, interleukin-4, and interleukin-6. Cytokine. 2:966-974.

25. Issekutz, T.B. 1990. Effects of six different cytokines on lymphocyte adherence to microvascular endothelium and in vivo lymphocyte migration in the rat. J. Immunol. 144:2140-2146.

26. Colditz, I.G., and D.L. Watson. 1992. The effect of cytokines and chemotactic agonists on the migration of T lymphocytes into skin. Immunology. 76:272-278.

27. Sljelid, R., and T. Eskeland. 1993. The biology of macrophages. I. General principles and properties. Eur. J. Haematol. 51:267-275.

28. Briscoe, D.M., R.S. Cotran, and J.S. Pober. 1992. Effects of tumor necrosis factor, lipopolysaccharide, and IL-4 on the expression of vascular cell ad- 
hesion molecule-1 in vivo: correlation with $\mathrm{CD}^{+} \mathrm{T}$ cell infiltration. J. Immunol. 149:2954-2960.

29. Mulligan, M.S., A.A. Vaporciyan, M. Miyasaka, T. Tamatani, and P.A. Ward. 1993. Tumor necrosis factor regulates in vivo intrapulmonary expression of ICAM-1. Am. J. Pathol. 142:1739-1749.

30. Silber, A., W. Newman, V.G. Sasseville, D. Pauley, D. Beall, D.G. Walsh, and D.J. Ringler. 1994. Recruitment of lymphocytes during cutaneous delayed hypersensitivity in nonhuman primates is dependent on E-selectin and vascular cell adhesion molecule 1. J. Clin. Invest. 93:1554-1563.

31. Springer, T.A. 1994. Traffic signals for lymphocyte recirculation and leukocyte emigration: the multistep paradigm. Cell. 76:301-314.

32. Miller, M.D., and M.S. Krangel. 1992. Biology and biochemistry of the chemokines: a family of chemotactic antiinflammatory cytokines. Crit. Rev. Immunol. 12:17-46.

33. Taub, D.D., K. Conlon, A.R. Lloyd, J.J. Oppenheim, and D.J. Kelvin. 1993. Preferential migration of activated CD $4^{+}$and $\mathrm{CD} 8^{+} \mathrm{T}$ cells in response to MIP-1 $\alpha$ and MIP-1ß. Science (Wash. DC). 26:355-358.
34. Miller, M.D., S. Hata, R. de Waal Malefyt, and M.S. Krangel. 1989. A novel polypeptide secreted by activated human $\mathrm{T}$ lymphocytes. J. Immunol. 143:2907-2916.

35. Zhou, Z., Y.J. Kim, K. Pollok, J. Hurtado, J.K. Lee, H.E. Broxmayer, and B.S. Kwon. 1993. Macrophage inflammatory protein-1 rapidly modulates its receptors and inhibits the anti-CD3 mAb-mediated proliferation of $\mathrm{T}$ lymphocytes. J. Immunol. 151:4333-4341.

36. Maltman, J., I.B. Pragnell, and G.J. Graham. 1993. Transforming growth factor $\beta$ : is it a downregulator of stem cell inhibition by macrophage inflammatory protein $1 \beta$ ? J. Exp. Med. 178:925-932.

37. Rathanswami, P., M. Hachicha, and M. Sadich. 1993. Expression of the cytokine RANTES in human rheumatoid synovial fibroblasts. J. Biol. Chem. 268:5834-5839.

38. Heeger, P., G. Wolf, and C. Meyers. 1992. Isolation and characterization of cDNA from renal tubular epithelium encoding murine RANTES. Kidney Int. 12:220-225. 